\title{
La dictadura cívico-militar brasileña en los discursos de Jair Bolsonaro: usos del pasado y negacionismo ${ }^{1}$
}

\author{
The Brazilian civic-military dictatorship in the \\ speeches of Jair Bolsonaro: uses of the past and ne- \\ gationism
}

\section{Caroline Silveira Bauer ${ }^{2}$}

\begin{abstract}
Resumen: Mi artículo busca reflexionar sobre los usos del pasado dictatorial brasileño en beneficio de la política contemporánea. Parto de la idea de que el presidente Jair Bolsonaro, como militar, forma parte de una "comunidad de memorias" sobre la dictadura que ha elaborado una suerte de relato memorial que ha conquistado estabilidad a lo largo del tiempo. Por otra parte, los usos que hace de ese pasado responden a la crisis institucional, económica, política y social vivida en Brasil, e intentan recuperar una identidad nacional muy específica.
\end{abstract}

Palabras clave: dictadura brasileña, memoria, usos del pasado, Jair Bolsonaro, negacionismo, revisionismo histórico.

Abstract: This paper aims to reflect on the uses of Brazil's dictatorial past for the benefit of contemporary politics. I start from the idea that President Jair Bolsonaro, being a military man, is part of a "community of memories" about the dictatorship that has produced a kind of memorial story that has conquered stability over time. Moreover, the uses made of that past respond to the institutional, economic, political and social crisis experienced in Brazil, and they try to recover a very specific national identity.

Keywords: Brazilian dictatorship, memory, uses of the past, Jair Bolsonaro, negationism, historical revisionism.

\footnotetext{
Doi: https://doi.org/10.24215/23142766e070

${ }^{1}$ Recibido: 30/05/2019. Aceptado: 19/09/2019.

2 Doctora en Historia por la Universidade Federal do Rio Grande do Sul y en Mon Contemporàni por la Universitat de Barcelona. Profesora del Departamento de Historia de la Universidade Federal do Rio Grande do Sul. Investiga las dictaduras de seguridad nacional y temas correlatos con financiación del CNPq. Correo eletrónico: caroline.bauer@ufrgs.br
} 
Sabemos que la memoria social es un proceso de construcción que registra, recalca, incluye y excluye recuerdos y olvidos, organizándolos y seleccionándolos. Es necesario jerarquizar acontecimientos, fechas y personajes; y esta jerarquización sufre cambios a lo largo del tiempo, puesto que la memoria responde, en parte, al tiempo presente de la articulación, y se relaciona con los intereses políticos y personales de su momento. Por eso, la memoria también es objeto de disputa para determinar qué es lo que será registrado y transmitido a las nuevas generaciones (JELíN, 2002).

La memoria sufre además cambios en función del presente en que es articulada, al interactuar con las preocupaciones y los intereses políticos del momento de su enunciación. Así, la memoria sobre la dictadura se constituye como un objeto de disputa constante, ${ }^{3}$ y son comunes los conflictos para determinar qué será registrado y transmitido a las nuevas generaciones.

Es justamente en la transmisión de la memoria que encontramos su conexión con el sentimiento de identidad, entendiendo memoria como las imágenes que creamos para nosotros mismos y para los demás y que nos hacen sentir parte de un grupo (POLLAK, 1992). La memoria puede articular sentimientos de permanencia, pertenencia y unidad en la reconstrucción de la narrativa del pasado. Incluso, puede haber memoria de lo que no se ha vivido: "en ese sentido, la memoria se conforma según el molde de esos relatos que siempre arrastran una dimensión mística, su trabajo no va del acontecimiento al recuerdo sino, al revés, de formaciones y marcos anteriores a la significación de acontecimientos [...]" (VEZZETTI, 2003:17).

Inevitablemente, para la construcción de esa identidad social, es necesaria la figura del Otro. Es imposible que este trabajo de construcción de la memoria prescinda de interacción, de refuerzo, de negociación o de transformación, en función de ese Otro. La construcción de la identidad es un proceso referencial, es decir, se hace con los demás y en referencia a ellos, y moviliza tanto aceptación como admisibilidad y credibilidad. La identidad, así, está en permanente negociación, y es por eso que las memorias se transforman a lo largo del tiempo, no siendo posible concebirlas como esencias de un grupo o una persona. Esto no significa que no tengamos grupos, "comunidades de memoria", en que determinado relato sobre el pasado tiene más o menos estabilidad. Dentro de las Fuerzas Armadas, institución cerrada y de poca crítica interna, permanece un relato sobre la dictadura que es bastante estable desde la década de 1960:

"La continuidad en las imágenes y sentidos del pasado, o la elaboración de nuevas interpretaciones y su aceptación o rechazo sociales, producen efectos materiales, simbólicos y políticos, e influyen en las luchas por el poder [...] Lo que se hace en un escenario y un momento dado depende de la trayectoria anterior del tema [...] y ésta condiciona (abre y cierra posibilidades) sus desarrollos futuros." (JELíN, 2009: 123)

La memoria de situaciones límite, como las dictaduras de los años 1960 y 1970, posee ciertas especificidades, según fueron analizadas por FRANCO e LEVÍN (2007:31):

[El pasado reciente] se trata de un pasado abierto, de algún modo inconcluso, cuyos efectos en los procesos individuales y colectivos se extienden

\footnotetext{
${ }^{3}$ Para una periodización del proceso de construcción de la memoria de la dictadura brasileña, verse el artículo de NAPOLITANO (2015).
} 
hacia nosotros y se nos vuelven presentes. De un pasado que irrumpe imponiendo preguntas, grietas, duelos. De un pasado que, de un modo peculiar y característicos, entreteje las tramas de lo público con lo más íntimo, lo más privado y lo más propio de cada experiencia. De un pasado que, a diferencia de los otros pasados, no está hecho sólo de representaciones y discursos socialmente construidos y transmitidos, sino que, además, está alimentado de vivencias y recuerdos personales, rememorados en primera persona. Se trata, en suma, de un pasado 'actual' o, más bien, de un pasado en permanente proceso de 'actualización' y que, por tanto, interviene en las proyecciones a futuro elaboradas por sujetos y comunidades.

Este artículo busca reflexionar sobre los usos del pasado dictatorial brasileño en beneficio de la política contemporánea. Se parte de la idea de que el presidente Jair Bolsonaro, como militar, forma parte de una "comunidad de memorias" sobre la dictadura que ha elaborado una suerte de relato memorial que ha conquistado estabilidad a lo largo del tiempo. Por otra parte, los usos que hace de ese pasado, en los términos de HARTOG y REVEL (2001), responden a la crisis institucional, económica, política y social vivida en Brasil, e intentan recuperar una identidad nacional muy específica.

En Brasil la dictadura comenzó el 31 de marzo de 1964 con una intervención militar en la política, apoyada por los sectores más conservadores de la sociedad, que se oponían a las reformas estructurales llevadas a cabo por el presidente João Goulart, un heredero del nacional-estatismo y defensor de la expansión de derechos fundamentales de la ciudadanía.

Es importante destacar que la de 1964 no fue la primera intervención de las Fuerzas Armadas brasileñas en la política. En realidad, la historia republicana brasileña, iniciada en 1889 , ha sido marcada por una sucesión de golpes militares y pronunciamientos militares que resultaron en la deposición de presidentes, cambios de régimen político, alteraciones en el orden constitucional, suicidios, entre otros acontecimientos. Pero a diferencia de las intervenciones de 1930, 1945, 1950, 1951, 1954 y 1961 -cuando los militares golpistas intervinieron y después pasaron el control del Estado a los civiles-, la intervención de 1964 marcó la historia brasileña - y latinoamericana - puesto que ellos permanecieron en el poder (ROUQUIÉ, SUFFERN, 1997:294-295), lo que dio comienzo a las llamadas "dictaduras de seguridad nacional", las cuales estaban marcadas por la lógica de la Guerra Fría, del "combate a la subversión" mediante el uso de enseñamientos de contrainsurgencia (Estados Unidos) y de la guerra revolucionaria (Francia), lo que dio como resultado el terrorismo de Estado (PADRÓS, 2005). Según las instituciones militares, las Fuerzas Armadas salvaron a la "civilización occidental y cristiana" (AGÜERO, HERSHBERG, 2005:15) y a la patria, cuyo futuro estaba amenazado por el comunismo ateo. Este régimen se mantuvo hasta la promulgación de la Constitución de 1988 y totalizó 24 años de dictadura. ${ }^{4}$

\footnotetext{
${ }^{4}$ En un libro publicado en 2014, el historiador Daniel Aarão Reis Filho (2014) propuso una nueva periodización para la dictadura brasileña, considerando los años entre 1979 a 1988 como un "Estado de derecho autoritario". Su propuesta ha sido muy criticada, y estamos de acuerdo con las críticas a él direccionadas. Sin embargo, el año de 1985 ha quedado inscripto en la historiografía y en la memoria social como el término de la dictadura sólo porque por la primera vez el presidente fue un civil. Pero, como sabemos, no es solo porque un presidente es civil que tenemos una democracia; de modo que adoptamos la perspectiva del término de
} 
La dictadura brasileña intentó construir mecanismos de legitimidad para no parecer un régimen de excepción (REZENDE, 2001) y eso influyó directamente en la formación de la memoria social sobre los años de autoritarismo -o "dictablanda", no "dictadura", como ha afirmado un periódico brasileño. Una de estas estrategias fue la utilización por parte de los militares del término "revolución" para referirse al su gobierno. "Revolución democrática de 31 de marzo" y "Revolución brasileña" han sido expresiones que utilizaron la valoración positiva que el concepto tenía en los años sesenta y setenta por representar la lucha contra la opresión y por independencia en el tercer mundo (CURTIS, 1999). Para distanciarse de una imagen dictatorial, los militares no vestían sus trajes de armas, siempre aparecían en público vestidos de civiles. Además, nadie hasta hoy les llama "dictadores" sino "presidentes militares" - un fenómeno raro el brasileño: una dictadura sin dictadores (REZENDE, 2001). Otra de las estrategias ha sido mantener en funcionamiento, aunque con una serie de límites, el parlamento, si bien el dictador legisla a través de decretos presidenciales conocidos como "Actos Institucionales", a través de los cuales, por ejemplo, se ha decretado la pena de muerte, la supresión del derecho a habeas corpus, las elecciones indirectas para cargos ejecutivos y la expulsión de ciudadanos del país, entre otros (REIS FILHO, 2002; MOTTA, 2018).

El modo como terminó la dictadura en Brasil también es muy importante para comprender la construcción de la memoria de ese período. La transición política duró mucho tiempo ${ }^{5}$ y dejó en evidencia el control que los militares y sus partidarios civiles tuvieron sobre el proceso y las narrativas que se harían sobre el pasado: no se abrirían los archivos de la represión, no se hablaría de los hechos, no habría actos "revanchistas". En el proceso de transición política, la preocupación de los grupos dirigentes sobre la gober-nabilidad los impulsó a evitar discusiones divisionistas respecto del pasado dictatorial. Además, los militares conservaron su sólida influencia durante la transición y los primeros gobiernos civiles, y ejercieron una influencia significativa sobre la Constitución de 1988 mediante considerable presión sobre el Congreso, principalmente en los temas de su propio interés, de la seguridad pública y de la amnistía de las violaciones de derechos humanos.

La larga transición brasileña contribuyó para olvidarse del terror implementado por la dictadura y para la dilución de la memoria colectiva. El proceso de normalización de la sociedad y de la política brasileña ha sido marcado por la interdicción del pasado, sea en la larga duración del proceso, donde el tiempo adquiere una dimensión inerte que en sí misma produce el olvido, sea en el aspecto de la imposición del olvido, a través de la ley de amnistía, cuya consecuencia fue la neutralización moral del pasado (CARDOSO, 2001:110).

Los momentos de cambio de régimen político, los períodos de transición, crean un escenario de confrontación entre actores con experiencias y expectativas políticas diferentes, generalmente contrapuestas. Y casa una de esas posturas involucra una visión del pasado y un programa (implícito en muchos

la dictadura en 1988 con la promulgación de una nueva Constitución y la realización de elecciones libres y directas. Para los distintos abordajes contemporáneos sobre la dictadura brasileña, véase FICO (2017).

${ }^{5}$ La transición hasta la democracia en Brasil fue la más larga de los cuatro países del Cono Sur, con su comienzo en el año de 1974. Creemos que la transición brasileña tuvo dos momentos distintos: el primero, de 1974 a 1984, puede ser definido como una "transición militar", y el segundo, de 1985 a 1988, como una transición civil. Sobre esa propuesta, véase BAUER (2019) y para más información sobre la transición política brasileña, véase FICO (2012). 
casos) de tratamiento de ese pasado en la nueva etapa que es definida como ruptura y cambio en relación con la anterior. (JELíN, 2002: 43)

El relato de las Fuerzas Armadas y el sentido que se le ha atribuido al pasado, luego de tres décadas de finalizada la dictadura, poco han cambiado, incluso cuando han sido cotejados con las "memorias subterráneas" (POLLAK, 1989) de ex-presos y perseguidos políticos, así como de familiares de muertos y desaparecidos que se manifestaron en el espacio público cuando hubo condiciones sociales de escucha y pasaron a confrontar públicamente la hegemonía narrativa de la dictadura, configurando una "batalla de memorias" (MARTINS FILHO, 2002; SCHMIDT, 2007; CARDOSO, 2011; MOTTA, 2013; PEREIRA, 2015; JOFFILY, 2018).

Esta influencia se ha hecho visible en la mantención de su versión sobre los hechos de las dos décadas y media de dictadura. El proceso de transición hasta la democracia no ha cambiado los sentidos atribuidos al pasado dictatorial y los relatos sobre la actuación de las Fuerzas Armadas, aunque se haya iniciado un proceso de conocimiento social sobre la dictadura como resultado de la realización de entrevistas, investigaciones y reportajes periodísticas, de lanzamiento de libros de memorias de expresos y perseguidos políticos y de las denuncias realizadas por movimientos sociales.

Ese relato, que cuenta con cohesión y estabilidad, hace de las Fuerzas Armadas una "comunidad de memorias" en cuyas representaciones del pasado los acontecimientos tienen menos importancia que las emociones que despiertan. Caracterizados por una retórica marcada por distorsiones e idealismos, esos discursos no necesariamente niegan la dictadura sino la justifican. El principal argumento se apoya en la tentativa de equiparación entre la violencia del Estado y la violencia revolucionaria, lo que en Argentina se llama "teoría de los dos demonios" (FEIERSTEIN, 2018). En el caso brasileño, la fuerza de esa cultura histórica se fundamenta en el "estigma de la cordialidad" (IOKOI, 2009:501-502), que busca neutralizar conflictos y disputas por medio de representaciones conciliatorias del pasado.

Por la jerarquización, obediencia y verticalidad propias de la institución militar, los discursos difundidos por los oficiales han pasado a ser compartidos por los miembros de esa "comunidad de memorias". Bolsonaro fue adoctrinado a partir de esos relatos sobre el pasado y ha asumido ese discurso como suyo para poder construir una identidad como miembro de las Fuerzas Armadas (AGÜERO, HERSHBERG, 2005). En el interior de las Fuerzas Armadas existen distintas concepciones y sentidos para el pasado dictatorial; sin embargo, por la jerarquización, obediencia y verticalidad propias de la institución militar, los discursos que son difundidos por sus líderes "forman parte del discurso comúnmente aceptado [por la institución]. En otras palabras, tales mensajes integran el tejido de significaciones compartidas por miembros de la comunidad militar" (PERELLI apud MUZZOPAPPA, 2005:108).

El panorama de la memoria social sobre la dictadura cívico-militar brasileña tiene como punto de inflexión el año de 2010.

Durante la segunda ronda de las elecciones presidenciales, la candidata Dilma Rousseff, con su pasado relacionado con su participación en organizaciones guerrilleras en los años 1960-1970, y de José Serra, quien durante el mismo período estuvo exiliado en Chile, se enfrentaron en una segunda ronda haciendo uso de sus experiencias personales 
durante la dictadura como un capital simbólico muy positivo. Ambos han sido "resistentes" a la dictadura (BAUER, 2014). Contrariamente a lo que se puede imaginar, ya que el presentismo nos retira la historicidad de los hechos, la diseminación de fake news y de negacionismos sobre la expresidenta empieza en 2010, cuando comenzó a ser llamada "terrorista" y acuasada de beneficiarse de una "beca-dictadura", como los sectores conservadores se refieren a las indemnizaciones recibidas por los perseguidos políticos. Así comenzó la difusión de mentiras sobre su trayectoria y las redes sociales tuvieron un papel muy importante en esa desinformación.

El gobierno de Dilma Rousseff promovió políticas públicas de memoria sobre la dictadura, entre las que se destaca la creación de la Comisión Nacional de la Verdad en 2011 (BAUER, 2017). Mientras desarrollaba sus trabajos, la sociedad debatía los sentidos de la dictadura. En la ola de manifestaciones nacionalistas de 2013, que demostraban la insatisfacción de la población, aparecieron las primeras demandas por el retorno de las Fuerzas Armadas al poder. La indignación se convirtió en odio y Bolsonaro supo aprovechar ese sentimiento como capital político, dándole inicio a la construcción de su candidatura para 2018.

En el año 2014 se celebró el cincuentenario del golpe de Estado e implantación de la dictadura. Las conmemoraciones en sí mismas traen consigo las disputas por la memoria, una evaluación de las políticas públicas desarrolladas en la democracia e incluso sus propios límites:

Las fechas y los aniversarios son coyunturas de activación de la memoria. La esfera pública es ocupada por la conmemoración, con manifestaciones explícitas compartidas y con confrontaciones. En términos personales y de la subjetividad, son momentos en que el trabajo de la memoria es arduo para todos, para os distintos bandos, para viejos y jóvenes, con experiencias vividas muy diversas. Los hechos se reordenan, se desordenan esquemas existentes, aparecen las voces de nuevas y viejas generaciones que preguntan, relatan, crean espacios intersubjetivos, comparten claves de lo vivido, lo escuchado o lo omitido. Son hitos o marcas, ocasiones cuando las claves de lo que está ocurriendo en la subjetividad y en el plano simbólico se tornan más visibles, cuando las memorias de diferentes actores sociales se actualizan y se vuelven 'presentes'. Aun en esos momentos, sin embargo, no todos comparten las mismas memorias (JELÍN, 2002:43).

Una encuesta realizada por el instituto Datafolha presentó la percepción de los brasileños sobre la democracia. Según esta encuesta, el $62 \%$ de los brasileños creía que la democracia siempre era mejor que cualquier otra forma de gobierno; al $16 \%$ no les importaba si el gobierno era una democracia o una dictadura; el 14\% defendía que, a veces, es mejor una dictadura; y el $8 \%$ no supo responder. Llama la atención el hecho de que el $38 \%$ de los entrevistados tuvieran dudas de si la democracia es la mejor forma de gobierno. ${ }^{6}$ Recordemos

\footnotetext{
${ }^{6}$ Encuesta disponible en: http://media.folha.uol.com.br/datafolha/2018/10/05/8243d5308d78b278a50aee22acd0c018DD.pdf Acceso: 30 de mayo de 2019.
} 
que "las memorias sociales están siempre enmarcadas socialmente. Estos marcos son portadores de la representación general de la sociedad, de sus necesidades y valores. Incluyen también la visión del mundo animada por valores, de una sociedad o grupo" (JELíN, 2002:20).

Por otra parte, el año 2014 fue un año electoral. La reelección de Dilma Rousseff fue cuestionada por su oponente y por los sectores conservadores de la sociedad, que tampoco la aceptaron. Las noticias falsas operaron como una forma de desestabilización del gobierno y, en esa coyuntura y casi tres años después, la Comisión Nacional de la Verdad entregó su informe final: un documento de 1300 páginas que reconocía la responsabilidad del Estado brasileño en las graves violaciones a los derechos humanos durante la dictadura. En 1300 páginas se reconocieron 434 muertes y desapariciones de disidentes políticos, además de 8 mil indígenas y de un incontable número de campesinos y de integrantes de la población negra. El informe incluyó testimonios de las víctimas, con una cantidad estimada de personas tortuardas que ascendía a entre 30 y 50 mil, y señaló con nombres y apellidos a 377 responsables de las graves violaciones a los derechos humanos (BRASIL, 2014).

En agosto de 2016, viviríamos la destitución de la presidenta. El proceso de juicio político ha generado una serie de comparaciones con el golpe de 1964; incluso Michel Temer, el presidente entronizado, fue comparado en la portada de la Revista Piauí con su congénere latinoamericano Augusto Pinochet. En esta coyuntura, el pasado ha sido movilizado mediante la recuperación del "fantasma del comunismo" y una nostalgia por la monarquía y el imperio brasileño, incluida la esclavitud. ${ }^{7}$ La recuperación de esa memoria se explica, como dijo Henri Rousso, por una voluntad de permanencia "de un sistema de comportamientos, valores o creencias en un mundo que cambia por definición."

Como hemos mencionado anteriormente, Bolsonaro realizó su formación durante las décadas de 1970 y 1980, y recibió una narrativa sobre la dictadura elaborada por oficiales que estuvieron directamente involucrados en las operaciones de represión a la oposición. Al ingresar a las Fuerzas Armadas, los individuos son convocados a formar parte de un 'nosotros' y a hacerse cargo de una historia institucional (AGÜERO, HERSHBERG, 2005). Gran parte de la socialización en las Fuerzas Armadas se realiza en un contexto de gran carga afectiva, fundamental para la delimitación de un 'nosotros'. La formación de una identidad "militar" alienta a las nuevas generaciones a involucrarse con una interpretación del pasado predeterminada, acudiendo a la transmisión de sus memorias como 'mecanismo cultural' para fortalecer un 'sentido de pertenencia'. Sabemos que el Ejército está regido por un conjunto de valores, tales como el honor, el deber, el patriotismo, la lealtad y la disciplina, y que para el militar la defensa de la patria es un destino superior. Bolsonaro encarna esos valores, y según afirma Jelín (2002: 35),

La memoria como construcción social narrativa implica el estudio de las propiedades de quien narra, de la institución que le otorga o niega poder y lo/a autoriza a pronunciar las palabras, ya que, como señala Bourdieu, la eficacia del discurso performativo es proporcional a la autoridad de quien

\footnotetext{
${ }^{7}$ Para un análisis de la crisis de 2016, véase MOTTA (2017) y NAPOLITANO (2018).
} 
lo enuncia. Implica también prestar atención a los procesos de construcción del reconocimiento legítimo, otorgado socialmente por el grupo al cual se dirige.

Jair Messias Bolsonaro nació en una familia pobre y numerosa del interior de la provincia de São Paulo. Durante la dictadura, vivió cerca de una región de conflictos entre las Fuerzas Armadas y la guerrilla, y su biógrafo nos dice que esto influyó para que siguiera la carrera militar. La caza de los comunistas y el espíritu de venganza acompañaron su adolescencia. Se conjuraban orden y obediencia, por un lado, y falta de respeto y agresividad contra los que no son los suyos, por el otro.

No resulta extraño, entonces, que sus asesores, hijos y algunos ministros se refieran a él como "el capitán", pero en las Fuerzas Armadas tenía el apodo de "cavalão", un aumentativo de caballo, debido a su personalidad. En 1986, con 31 años, escribió un artículo en el que se quejaba de los bajos sueldos de los militares. A causa de ese texto fue detenido y sufrió un proceso militar por indisciplina. Entusiasmado con el apoyo recibido por sus compañeros de armas, desarrolló un plan que consistía en explotar bombas de baja potencia en cuarteles y academias militares para reclamar por los bajos salarios. Nuevamente procesado, tuvo que dejar el Ejército y, una vez retirado, ingresó en la política, primero, como concejal de la ciudad de Río de Janeiro y, más tarde, como diputado federal, cargo que ejerció durante 24 años. Era considerado un outsider y se preocupaba en defender los intereses de los militares.

El éxito en las elecciones de 2018 se explica, en parte, según el psicoanalista brasileño Christian Dunker, porque Bolsonaro representa la figura paterna a la que todos tenemos miedo y a la que nos sometemos a cambio de protección. ${ }^{8}$ Bolsonaro crea identificaciones por medio de su odio y por medio de su personificación de las Fuerzas Armadas, que en Brasil cuentan con un prestigio del que no gozan en ningún otro país del Cono Sur. Los analistas le atribuyen este prestigio a las estrategias de legitimación de la dictadura, a la forma como se realizó la transición a la democracia y a una histórica imagen de las Fuerzas Armadas identificadas con el orden y con la propia idea de Brasil.

[A]l igual que en el pasado, políticos, partidos y electores, al adoptar sus decisiones políticas, se orientan por regla general por las ideas que tienen sobre el posible discurrir del acontecer futuro. Esas ideas de reflejan de diversas maneras en los programas de los partidos, las declaraciones de los gobiernos, las encuestas y los documentos; ocupan amplio espacio en los discursos electorales y en los escritos sobre la política del día, pero, de manera más invisible, determinan en el fondo el juicio político de las personas. Con frecuencia no se trata únicamente de objetivos positivos, sino también de la expectativa de acontecimientos o procesos que se valoran negativamente y que habría que rechazar o evitar. (HÖLSCHER, 2014: 232)

Las Fuerzas Armadas, como nos dicen Felipe Agüero y Eric Hershberg (2005:3), "en su calidad de portadoras de mitos nacionales y nacionalistas" y de "agentes transmisores del sentimiento patriótico" son instituciones "interesadas en dar continuidad a una visión tradicional de la construcción y unificación nacional”. Según estos autores (2005: 31),

\footnotetext{
8 DUNKER, Christian. A sombra de si mesmo. Disponible em: https://epoca.globo.com/a-sombra-de-simesmo-23184248 Aceso: 30 may. 2019.
} 
Existe una identificación constante de los militares con la nación, comprendida como indivisible y encarnada en imágenes de la patria [...] Esto es crucial, dado que la experiencia de la represión, siempre y cuando se reconozca que ha sucedido, se contextualiza en consecuencia como una obligación necesaria, a menudo penosa, arraigada en el compromiso de proteger la integridad y seguridad de la nación. Visto así, cuestionar el rol de los militares en estos acontecimientos - negar, por ejemplo, que existieron tales amenazas a la nación o que la represión estuvo dirigida a dichas amenazas antes que al intento de generar un clima de temor generalizado en ciertos segmentos de la población - es muchas veces recibido como un ataque a la institución de las Fuerzas Armadas y cono un reto a la nación.

Hasta el momento, Bolsonaro ha sido el presidente que ha nombrado más militares en los niveles más altos del gobierno después de la dictadura. Su vicepresidente, un general, dijo en una entrevista al periódico El País: "Los grupos marxistas y leninistas de Brasil decían que se estaban enfrentando a la dictadura, pero en verdad estaban luchando para imponer otra dictadura, la del sistema comunista. Fue una guerra muy pequeña para un país de 90 millones de habitantes [en la época]. De los dos lados, sumando, murieron poco más de 400 personas. Hoy, matan a 60.000 en Brasil al año y nadie habla al respecto". ${ }^{9}$

La frustración con los políticos y con la política, y las soluciones extremas para resolver la violencia y la corrupción, movilizaron a los partidarios del Bolsonaro, quien personifica a las Fuerzas Armadas y encarna la fuerza, la salud, la potencia y la esencia guerrera, unidas a la virilidad, y se contraponen a las comodidades o el dinero. Como sostiene Jelín (2002:74), "cuando nuevos actores o nuevas circunstancias se presentan en el escenario, el pasado es resignificado y a menudo cobre una saliencia pública inesperada". Esto puede verse cuando, después del atentado que sufrió pocas semanas antes de las elecciones, Bolsonaro se convirtió en un héroe trágico.

Pues, entonces, llegamos al momento de analizar tres instancias de manifestaciones de Bolsonaro sobre la dictadura. En los últimos años, el debate sobre la dictadura ha tomado el espacio público y se ha convertido en una cuestión de poder y política, en parte por la dimensión de la represión y de los efectos residuales de la dictadura, como la impunidad. En palabras de Caviglia (2006: 52), "la disputa sobre la memoria incide de manera directa en el desenlace de enfrentamientos políticos presentes. [...] Pues si la memoria es la forma en que el pasado existe en el presente, sin duda esa memoria también es y será, al menos por ahora, objeto de una disputa por el futuro político".

1) La primera de las instancias ocurrió en el 2009, cuando aún era diputado federal. En la puerta de vidrio de su despacho parlamentario, Bolsonaro colgó un cartel que rezaba: "Desaparecidos del Araguaia: los que buscan huesos son los perros". Las palabras son del mayor Curió, que en los años 1970 comandó las operaciones de tortura, exterminio y desaparición

\footnotetext{
${ }^{9}$ Disponible en https://elpais.com/internacional/2019/03/26/actualidad/1553608686 952253.html Acceso: 26 de septiembre de 2019
} 
de cuerpos en la Guerrilla del Araguaia y se refieren a los trabajos de búsqueda e identificación de los restos mortales de los guerrilleros, tareas emprendidas por el gobierno y por organizaciones de la sociedad civil.

2) La segunda manifestación, también cuando aún era diputado federal, ocurrió el 17 de abril de 2016, en la sesión de la Cámara de Diputados que aprobó la destitución de Dilma Rousseff. En esa ocasión, al declarar su voto aprobatorio, Bolsonaro dijo: "Han perdido en 1964, perdieron ahora en 2016. Por la memoria del coronel Carlos Alberto Brilhante Ustra, el terror de Dilma Rousseff, por Brasil por encima de todo y Dios por encima de todos, mi voto es sí." ${ }^{10}$ Brilhante Ustra, coronel del Ejército, es un reconocido torturador de la dictadura y fue quien torturó personalmente a Dilma Rousseff. Incluso, ha escrito libros negacionistas cuya lectura está siendo recomendada en las escuelas brasileñas y Bolsonaro ha dicho que los textos de Ustra son sus "libros de cabecera". La declaración de Bolsonaro, además de una referencia al pasado reciente brasileño, le ha otorgado legitimidad a toda una serie de narrativas y representaciones negacionistas de la historia de la dictadura. Nuevamente, la especificidad del negacionismo brasileño: no niega, no revisa, busca legitimidad para la dictadura.

3) Ya como presidente, en el mes de febrero próximo pasado, Bolsonaro se encontró con el presidente paraguayo Mario Abdo Benítez para anunciar el nombramiento de nuevas autoridades para la represa de Itaipú, represa que ambos países comparten sobre el río Paraná. En su discurso, Bolsonaro enalteció al dictador Alfredo Stroessner, quien comandó una dictadura en Paraguay entre los años 1954 y 1989. Bolsonaro dijo que la represa no habría sido posible "si no fuera porque al otro lado había un hombre de visión, un estadista que sabía perfectamente que su país, Paraguay, solamente podría seguir progresando si tuviese energía [...]. Entonces aquí mi homenaje a nuestro general Alfredo Stroessner."11

Posteriormente, a mediados de marzo, tras una visita a Yad Vashen en Israel, Bolsonaro dijo que es posible perdonar el Holocausto y que "no hay duda de que el nazismo fue un movimiento de izquierdas" 12 .

Pocos días después, el 31 de marzo, en el aniversario del golpe de 1964, Bolsonaro se encontraba en Santiago de Chile. En esa visita, el ministro jefe de la Casa Civil, Onyx Lorenzoni, al defender la reforma del sistema de pensiones en Brasil, utilizó el ejemplo de la dictadura chilena con la siguiente afirmación: "En Chile, en el pasado, tuvo que haber un baño de sangre para que se aprobaran principios macroeconómicos".

Finalmente, tenemos la autorización para que se festeje el golpe de 1964. La efeméride fue discretamente celebrada durante años en cuarteles y clubes militares. Pero en marzo de 2019, Bolsonaro ordenó a su portavoz, el general Otávio Rêgo Barros, que comunicara que había determinado como acto de gobierno la debida celebración del golpe de 1964 , enalteciendo la memoria militar. Sabemos que las fechas conmemorativas tienen sentidos diferentes para los distintos grupos sociales y que las memorias construidas en esas

\footnotetext{
${ }^{10}$ Disponible en https://www.elmundo.es/america/2016/07/09/578123a5468aebf23c8b45db.html Acceso: 30 de mayo de 2019.

${ }^{11}$ Disponible en: https://www.publico.es/politica/bolsonaro-homenajea-dictador-paraguayo-alfredostroessner.html Acceso: 30 de mayo de 2019

12 GALARRAGA GORTÁZAR, Naiara. El caótico arranque del Gobierno Bolsonaro en Brasil. Disponible en: https://elpais.com/internacional/2019/04/13/actualidad/1555170195_027248.html Acceso: 30 de mayo de 2019
} 
coyunturas se revisten de las luchas políticas del presente. En ese ritual público autorizado por Bolsonaro, el pasado se hace presente y "se activan sentimientos y se interrogan sentidos, en que se construyen y reconstruyen las memorias del pasado. Son momentos en que diferentes actores de cada país eligen para expresar y confrontar, en el escenario nacional, los sentidos que otorgan a los quiebres institucionales que unos impulsaron y otros/as sufrieron" (JELÍN, 2002b: 1).

Al determinar que se celebre el golpe militar de 1964, el presidente busca mantener el odio activo, convirtiendo el negacionismo en una política de memoria. Bolsonaro ha creado condiciones, "marcos sociales de la memoria" (HALBWACHS, 2004), para legitimar el discurso negacionista, a partir de una representación que pone énfasis en el grupo en cuanto grupo, anterior y contrapuesto al individuo, lo que nos permite comprender cómo tantos jóvenes nacidos dos décadas después del fin de la dictadura afirmen lo bueno que era vivir en ese período. ${ }^{13}$ Existe una importante identificación con ese pasado, porque a esos jóvenes el futuro se les muestra cerrado. En palabras de Mudrovcic (2009: 19), "es en la escena pública donde ponemos en cuestión no sólo lo que debe creerse del pasado sino además los valores que deben implantarse en el presente para una mejor proyección social de nuestro futuro. La historia nos ofrece un importante aporte en la medida en que debería esclarecernos acerca de nuestro pasado".

Esta es tan solo una selección de manifestaciones de Bolsonaro a favor de la dictadura, pero los registros son mucho más numerosos. El capitán retirado nunca ha ocultado su nostalgia por la dictadura que se prolongó por más de dos décadas.

El negacionismo, al realizar apología a la dictadura, refuerza marcadores de exclusión en la sociedad brasileña. Una frase que se repite mucho en Brasil es "qué bueno que era vivir en la dictadura" y trae entrelíneas la visión de una sociedad que valoriza la autoridad, la jerarquía y prácticas de control y represión en que los papeles sociales de mujeres, negros, gays y pobres son preestablecidos e inmutables. De cierta manera, Bolsonaro ha convencido a su electorado de que las minorías les han robado el espacio identitario, uno indivisible e inmutable, de lo que se considera "brasileño". Según Jelín (2002:69), "los cambios en escenarios políticos, la entrada de nuevos actores sociales y las mudanzas en las sensibilidades sociales inevitablemente implican transformaciones de los sentidos del pasado".

El dilema de definir qué es ser brasileño está presente desde el proceso de independencia de Brasil en el siglo XIX -y aquí creo que es importante remarcar las diferencias en los procesos de construcción de identidades nacionales en metrópolis y colonias. En Brasil fue necesario crear una historia y una memoria que rompiera con Portugal pero que, a la vez, se diferenciara de las excolonias españolas en América (asociadas al caos y a la división de los primeros años post-independencia) y, además, que abarcara al negro, al indígena y al blanco como formadores de la sociedad. Fue necesario crear un discurso de unidad en un relato histórico que en nada coincidía con la heterogeneidad cultural, étnica, histórica y lingüística del vasto territorio brasileño (BENTIVOGLIO, 2015; GUIMARÃES, 1988, GUIMARÃES, 1995). Y ese dilema atravesó todo el siglo XX y ha vuelto con mucha fuerza en una coyuntura de crisis a partir de los años 2010. No es fortuito que esa "reactualización" de la narrativa

\footnotetext{
${ }^{13}$ De acuerdo con la Comisión Nacional de la Verdad, "oitenta e dois milhões de brasileiros nasceram sob o regime democrático. Mais de oitenta por cento da população brasileira nasceu depois do golpe militar." Véase nota de CNV sobre os 50 anos do golpe de 1964. Disponible en: <https://goo.gl/NxGpQn>. Último acesso: 7 de agosto de 2017.
} 
sobre la dictadura, que crea la idea de un pasado mítico, ocurra en un momento de crisis económica e institucional.

En este sentido, el gobierno de Bolsonaro invierte en el proceso de "encuadramiento de la memoria" (POLLAK, 1998) a partir de determinada comprensión de la historia que remonta a los métodos del siglo XIX. En otras palabras, defiende que hay que recuperar el sentimiento de unidad, continuidad y coherencia que se han "fragilizado" con el reconocimiento de la diversidad existente en Brasil. Por eso, el apelo al nacionalismo y al patriotismo por medio de las Fuerzas Armadas y de Bolsonaro como figuras leales a la nación, utilizando el esencialismo para definir qué es ser brasileño.

El regreso a la dictadura en el presente se da, en parte, por una búsqueda de orientación en el pasado, pero no en el pasado real, sino en un pasado que nunca ha existido. La dictadura es narrada como una utopía que mejoraría la economía y la seguridad porque, según ellos, la dictadura ha tenido éxito en esos aspectos. La relación entre coyunturas de crisis y la reformulación de memorias ya han sido esbozadas por Pollak (1992) y por Jelín (2002:20):

Los períodos de crisis internas de un grupo o de amenazas externas generalmente implican reinterpretar la memoria y cuestionar la propia identidad. Estos períodos son precedidos, acompañados o sucedidos por crisis del sentimiento de identidad colectiva y de la memoria. Son los momentos en que puede haber una vuela reflexiva sobre el pasado, reinterpretaciones y revisionismos, que siempre implican también cuestionar y redefinir la propia identidad grupal.

Bolsonaro solamente puede existir en un país en el que se asume vivir en una guerra interna, razón por la cual él trata de alimentar esa guerra. La determinación oficial de festejar el golpe de 1964 es parte de esta estrategia y tememos mucho que la violencia simbólica del negacionismo y de la "batalla de la memoria" termine convirtiéndose en violencia concreta y real.

\section{Bibliografía}

Agüero, Felipe, Hershber, Eric (2005). Las Fuerzas Armadas y las memorias de la represión en el Cono Sur. In: AGÜERO, Felipe, HERSHBERG, Eric (comps). Memorias militares sobre la represión en el Cono Sur: visiones en disputa en dictadura y democracia. Madrid: Siglo XXI, 2005.

Bauer, Caroline Silveira (2014). Brasil e Argentina: ditaduras, desaparecimentos e políticas de memória. Porto Alegre: ANPUH-RS, 2014.

Bauer, Caroline Silveira (2017). Como será o pasado? História, historiadores e a Comissão Nacional da Verdade. Jundiaí: Paco.

Bauer, Caroline Silveira (2019). Presenças da ditadura e esperanças na Constituição: as demandas da população sobre a prática da tortura. Estudos Ibero-americanos, Porto Alegre, v. 45, n. 1, p. 91-103, jan.-abr. 2019.

Bentivoglio, Julio (2015). “A história no brasil imperial: a produção historiográfica na revista do Instituto Histórico e Geográfico Brasileiro (1839-1850)". História: Questões 
\& Debates, Curitiba, volume 63, n.2, p. 287-315, jul./dez. 2015. Editora UFPR.

Brasil. Comissão Nacional da Verdade. Relatório. Brasília: CNV, 2014.

Cardoso, Irene (2001). Para uma crítica do presente. São Paulo: Editora 34.

Cardoso, Lucileide Costa (2011). "Os discursos de celebração da 'Revolução de 1964'”. Revista Brasileira de História. São Paulo, v. 31, n. 62, p. 117-140, 2011

Caviglia, Mariana (2006). Dictadura, vida cotidiana y clases medias: una sociedad fracturada. Buenos Aires: Prometeo Libros.

Curtis, Regina Maria Gonçalves (1999). 1964 e a Revolução no Brasil: representações e imaginário social (1964-1973). Porto Alegre. Programa de Pós-Graduação em História - Universidade Federal do Rio Grande do Sul (dissertação de Mestrado), 1999.

Feierstein, Daniel (2018). Los dos demônios (recargados). Buenos Aires: Marea.

Fico, Carlos (2012). Brasil: a transição inconclusa. In: Carlos Fico; Maria Paula Araujo; Monica Grin. (Org.). Violência na História: memória, trauma e reparação. Rio de Janeiro: Ponteio, 2012, p. 25-37.

Fico Carlos (2017). Ditadura militar brasileira: aproximações teóricas e historiográficas. Tempo E Argumento, v. 09, p. 05-74, 2017.

Franco, Marina, Levín, Florencia (2007). El pasado cercano en clave historiográfica. In: FRANCO, Marina, LEVÍN, Florencia (comps.). Historia reciente: perspectivas y desafíos para un campo en construcción. Buenos Aires: Paidós, 2007.

Guimarães, Lúcia M. Paschoal (1995). “Debaixo da imediata proteção de Sua Majestade Imperial: o Instituto Histórico e Geográfico Brasileiro (1838-1889)”. Revista do IHGB, Rio de Janeiro, no 388, jul./set.,1995.

Guimarães, Manoel L. Salgado (1988). “Nação e civilização nos trópicos: o Instituto Histórico e Geográfico Brasileiro e o Projeto de uma História Nacional". Estudos Históricos, Rio de Janeiro, n. 1, 1988.

Halbwachs, Maurice (2004). Los marcos sociales de la memoria. Caracas: Universidad Central de Venezuela.

Hartog, François, Revel, Jacques (2001) (orgs.). Les usages politiques du passé. Paris : EHESS.

Hölscher, Lucian. El descubrimiento del futuro. Madrid: Siglo XXI, 2014.

lokoi, Zilda Márcia Gricoli (2009). A longa transição de conciliação ou estigma da cordialidade: democracia descontínua e de baixa intensidade. In: SANTOS, Cecília MacDowell, TELES, Edson, TELES, Janaína de Almeida (orgs.). SANTOS, Cecília Macdonell, TELES, Edson, TELES, Janaína de Almeida (orgs.). Desarquivando a ditadura: memória e justiça no Brasil. São Paulo: Hucitec, 2009. 2 v.

Jelín, Elizabeth (2002). Los trabajos de la memoria. Madrid: Siglo XXI.

Jelín, Elizabeth (2002b). Introducción. In: JELIN, Elizabeth (comp.). Las conmemoraciones: las disputas en las fechas <<infelices >>. Madrid: Siglo XXI, 2002b.

Jelín, Elizabeth. ¿Quiénes? ¿Cuándo? ¿Para qué? Actores y escenarios de las memorias. In: 
Vinyes, Ricard (ed.). El Estado y la memoria: gobiernos y ciudadanos frente a los traumas de la historia. Barcelona: RBA, 2009.

Joffily, Mariana (2018). “Aniversários do golpe de 1964: debates historiográficos, implicações políticas". Tempo e Argumento, Florianópolis, v. 10, n. 23, p. 204-251, jan./mar. 2018.

Martins Filho, João Ribeiro (2002). “A guerra da memória: a ditadura militar nos depoimentos de militares e militantes". Varia História, Minas Gerais, n. 28, dez. 2002, p. 178-201

Motta, Rodrigo Patto Sá (2013). História, Memória e as disputas pela representação do passado recente. Patrimônio e Memória (UNESP), v. 9, p. 56-70, 2013.

Motta, Rodrigo Patto Sá (2018). Sobre as origens e motivações do Ato Institucional 5. Revista Brasileira De História (Online), v. 38, p. 195-216, 2018.

Motta, Rodrigo Patto Sá (2017). Giro a la derecha e impeachment: la crisis política de Brasil. Revista Política Latino-Americana, v. 5, p. 15-25, 2017.

Mudrovcic, María Inés. Introducción. Representar pasados en conflicto. In: Mudrovcic, María Inés (ed.). Pasados en conflicto: representación, mito y memoria. Buenos Aires: Prometeo Libros, 2009. p. 19.

Muzzopappa, María Eva (2005). Savia nueva de un árbol eterno. Ejército, jóvenes y memoria en la Escuela Militar (Chile, 1971-2002) In: HERSHBERG, Eric, AGÜERO, Felipe (comps.). Memorias militares sobre la represión en el Cono Sur: visiones en disputa en dictadura y democracia. Madrid: Siglo XXI, 2005.

Napolitano, Marcos (2015). Recordar é vencer: as dinâmicas e vicissitudes da construção da memória sobre o regime militar brasileiro. Antíteses, Londrina, v. 8, p. 9-44, 2015.

Napolitano, Marcos (2018), « La crise politique brésilienne : histoire et perspectives d'une 'terre en transe' », Brésil(s) [En ligne], 1 | 2018, mis en ligne le 16 juillet 2018, consulté le 26 septembre 2019. URL : http://journals.openedition.org/bresils/2687

Padrós, Enrique Serra (2005). Como el Uruguay no hay... Terror de Estado e Segurança Nacional. Uruguai (1968-1985): do Pachecato à Ditadura Civil-Militar. Porto Alegre: UFRGS, 2005. 850 f. Tese (Doutorado em História) - Programa de Pós-graduação em História, Universidade Federal do Rio Grande do Sul, Porto Alegre, 2005.

Pereira, Mateus. H. F (2015). “Nova Direita? Guerras de memória em tempos de Comissão da Verdade (2012-2014)”. Varia História, Minas Gerais v. 31, 2015. p. 863-902.

Pollak, Michael (1992). "Memória e identidade social”. Estudos Históricos, Rio de Janeiro, v. 5, n. 10, 1992, p. 200-212.

Pollak, Michael (1989). “Memória, esquecimento, silêncio”. Estudos Históricos, Rio de Janeiro, v. 2, n. 3, 1989, p. 3-15.

Reis Filho, Daniel Aarão (2002). Os muitos véus da impunidade: sociedade, tortura e ditadura no Brasil. Disponível em: www.gramsci.org . Acesso em: 15 set. 2002 
Reis Filho, Daniel Aarão (2014). Ditadura e democracia no Brasil. Rio de Janeiro: Zahar, 2014.

Rezende, Maria José de (2001). A ditadura militar no Brasil: repressão e pretensão de legitimidade (1964-1984). Londrina: UEL.

Rouquié, Alain, Suffern, Stephen (1997). Los militares en la política latinoamericana desde 1930. In: Bethell, Leslie (org.). Historia de América Latina: política y sociedad desde 1930. Barcelona: Crítica.

Rousso, Henry. Los usos políticos del pasado: historia y memoria - para una historia de la memoria colectiva - la post-Vichy. Disponible en http://www.comisionporlamemoria.org/static/prensa/jovenesymemoria/bibliografia_web/historia/Rousso.pdf Aceso 26 sep. 2019.

Schmidt, Benito Bisso. "Cicatriz aberta ou página virada? Lembrar e esquecer o golpe de 1964 quarenta anos depois". Anos 90, Porto Alegre, v. 14, n. 26, p. 127-156, dez. 2007.

Vezzetti, Hugo (2003). Pasado y presente: guerra, dictadura y sociedad en la Argentina. Buenos Aires: Siglo XXI. 


\section{Revista de}
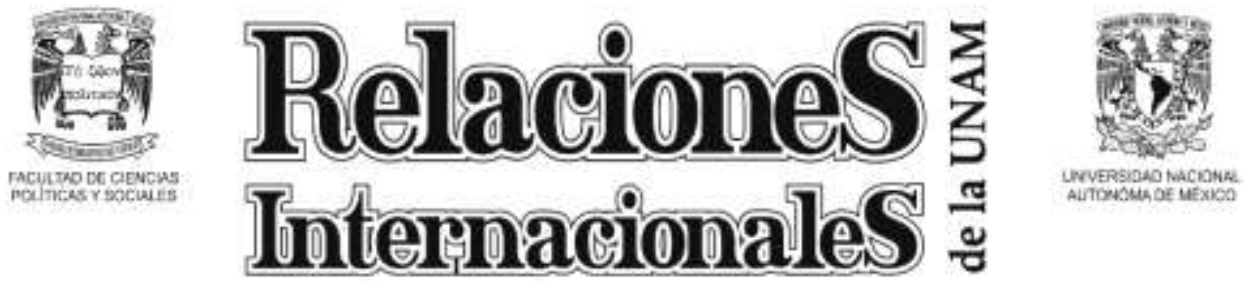

Septiembre-diciembre $2019 \quad 135$

Indice

\section{ARtículos}

Retos de la politica migratoria del Estado mexicano

José Eduardo Rojo Oropeza

Migrantes indocumentados en y tras el eruce de la frontera Sonora/Arizona:

vulnerabilidad y factores de supervivencia

Olga Aikin Araluce / Adriana Gonzälez Arias

El Acuerdo sobre Facilitsción del Comercio de la OMC en Argentina.

Avances y desafios en el proceso de implementación (2015-2019)

Juan Manucl Padin

Las negociaciones del Mercosur: trayectorias bilaterales para la construcción de consensos

Lorena Granja Hernández

Efectos de la caida de Saddam Husein en el Kurdistán Iraqui

Jefferson Efrain González Isaza

\section{Notas}

Retos de la cooperación al desarrollo de la Unnión Europea con México en el nuevo orden mundial Enriqueta Serrano

Rutas comerciales en Mesoamériea, la formación del sistema internacional prehispánico

Salimah Cossens

RESEÑAS

\section{Cronología de la Politica Exterior de México}

Informes y suscripciones:

Facultad de Ciencias Políticas y Sociales, UNAM

Circuito Cultural "Mario de la Cueva", Edificio "G", Planta Baja,

C. P, 04510, Ciudad Universitaria, Alcaldia Coyoacán, Ciudad de México

Tel.: 5622-9470, extensión 1060 o 1061 .

Correo electrónico: suscripciones.fcpys@gmail.com 